\title{
School Segregation Policy and Its Educational Ramifications for Internal Migrant Children in Urban China
}

\author{
Ting Liu ${ }^{1,2} \&$ Ronald S. Laura ${ }^{3}$ \\ ${ }^{1}$ Lecturer in Education, Faculty of Education, East China Normal University, Shanghai, China \\ ${ }^{2} \mathrm{Ph} . \mathrm{D}$, The University of Newcastle, Australia \\ ${ }^{3}$ Professor in Education, The University of Newcastle, Australia \\ Correspondence: Ting Liu, Lecturer in Education, Faculty of Education, East China Normal University, Shanghai, \\ China.
}

Received: May 8, 2017

Accepted: May 30, 2017

Online Published: June 5, 2017

doi:10.20849/ajsss.v2i2.158

URL: https://doi.org/10.20849/ajsss.v2i2.158

\begin{abstract}
This paper reviews the current state of education for internal migrant children in urban China, with the aim of teasing out its ramifications for pedagogic equity expressed as performance outcomes. In recent years migrant children have been segregated predominantly in urban migrant schools, whereas students with a higher socioeconomic status may have access to integrated public schools populated mostly by urban children. This paper analyses publicly accessible policy papers and relevant scholarly literature to provide a contextualised interpretation of school segregation, with an aim to advance societal recognition of and responsibility for the inequities associated with the education of migrant children in China. Our intention is to tease out and make more transparent than has to date happened the implications of these disparities and inequities. It is to be hoped that this information will encourage policy makers to acknowledge that the amelioration of inequities in performance depends on reforming the current segregation procedures and administrative protocols which fail to maximise the access to equal educational opportunities to which Chinese migrant students should be entitled.
\end{abstract}

Keywords: school segregation, urban education, internal migration, inequity, urban China

\section{Introduction}

Given China's rapid economic development and the sociocultural changes engendered, it is perhaps unsurprising that Chinese society has experienced a beneficent emancipation from approximately 5000 years of feudal tradition with its rigorous residency control of rural people. Indeed, China has begun to embrace its own transformation into a relatively tolerant society which, amongst many advances, has made it easier for rural people to relocate into urban areas. China proclaims that its 'National New-type Urbanization Plan (2014-2020)' aims to target 60 percent of its people living in urban cities by 2020, and to grant 100 million rural-urban migrants with 'urban household designation' (Hukou) (National People's Congress, 2014). Historically, there has long existed a dualistic class system which has structurally embedded a hiatus between populations from rural areas and those from urban areas. In essence this dichotomy engendered the polarisation of Chinese people who were covertly divided into two categories, one of which was stereotyped as agricultural (e.g. drawn from rural areas) and the other of which was identified as non-agricultural (e.g. residing in urban areas). What has not been sufficiently appreciated is the extent to which students from rural areas have been prohibited from obtaining equal resources in terms of welfare, employment, and the attainment of public goods. In comparison to the privileges enjoyed by urban students, rural students have been systematically deprived of many the entitlements available to urban students (Wei and Hou, 2010).

Moreover, the system of household registration strictly controls the migration between rural and urban areas. With the development of urbanization since the 1980 s, large numbers of rural people have migrated to urban areas for more opportunities of employment. However, limited by the household registration system, urban education settings have not been able to provide the opportunities for school access anticipated by children from migrant families. These migrant children are classified as being 'out-of-district' children seeking education in urban public schools (Liu and Jacob, 2013). Given that considerable pressure has accumulated within the international community that educational equity should be made provided for all children in China, the issue of 
the particular ways in which the education of rural-urban migrant children should currently be determined takes on a role of national importance. This being so, we will argue that emergent policies on rural-urban migrant children in China have come to figure more prominently in diminishing the chances of academic success for Chinese migrant students than was originally idealised.

\section{Global Issues of Internal Migrant Children}

The process of urbanization has significantly reinforced the rural-urban migrant movement in many countries, not just China. For example, in North American and in many European countries, early school segregation has proven to be most negatively pronounced in the largest metropolitan areas. Studies have established, for example, that in the US public school disparities in the segregation of school children represent scenarios which reflect not only components of racial composition and ethnic school segregation (Clotfelter, 1999), but are also based significantly on 'socio-economic status' (SES) (Deshingkar and Grimm, 2005, Frankenberg et al., 2010). Despite years of effort to institutionalize the 'US Civil Rights Project of School Desegregation', it is lamentable that some urban schools continue to place children in disadvantaged and academically disabling schooling environments. In Russia, the impacts of migration on children's socialization have been well documented, and migrant children were considered to be amongst the most disadvantaged and 'performance problematic' populations in schools (Lialiugene and Rupshene, 2008).

In Asian countries such as Pakistan and Bangladesh segregation education has also resulted in the labelling and stigmatization of migrant children, both of which act as impediments to social inclusion on the one hand, and instantiations of educational exclusion on the other (Kang, 2010). In India, a similar version of the same story can be told, coupled with the fact that in India children migrate from rural to urban areas not just for access to education but for labor opportunities, due to extreme poverty and various forms of violence enacted upon them, including heinous types of domestic abuse (Iversen, 2002). Given that migrant children around the globe are confronted with relentlessly challenging situations of inferior educational opportunity, the lamentable problem of disparities in academic achievement between segregated and non-segregated schools desperately needs to be resolved .Given the widespread occurrence of educational inequity, it is important to be clear that the problem is not an anomaly peculiar to China, with the exception that the number of students involved is much greater (Garcia, 2008) This being so, it should also be clear also that in China a large portion of rural-urban migrant families with a massive underclass population residing in urban areas is all too common and presents a monumental difficulty for the educational system in China ( $\mathrm{Lu}$ and Zhou, 2013).

In order to resolve, or even ameliorate the problem it is necessary to make its aetiology transparent. It is evident and reasonably well-recognised among scholars in the field that the consistently low academic performance outcomes of migrant children in China have derived predominantly from their inability to gain access to urban public schools with better physical and human resources (Lai et al., 2014). What has not been satisfactorily addressed is why this situation has occurred. The central objective of this paper is to rectify 'tis deficiency. Our argument is that despite the slowly growing body of literature which confirms the educational inequities confronting migrant students, (Agirdag, et al., 2013, Dronkers and Levels, 2007), the aetiology of the problem has not yet been adequately exposed. We submit that the real source of the problem is the failure of the 'school segregation legislation policy' itself. That migrant students have for the most part been sequestered in migrant schools with poor resources explains why their isolation has led ineluctably to their poor performance outcomes when compared to students in urban schools. What is not explained is that it is the segregation legislation policy that has created the structural source of the inequities confronting migrants by legislatively restricting their access to urban schools. In consideration of the substantial sociopolitical barriers associated with the policy, it has forced a large sector of Chinese migrant children to be kept segregated in low-quality migrant schools, and in turn thus denied the opportunities reserved for urban students. This being so, it is evident that the Chinese policy of school segregation functions as an inhibitory structural mechanism, and in turn fosters an educational context within which Chinese migrant children are obliged to experience a lesser quality education than is provided in non-migrant schools in urban locations.

In the section that follows we will endeavor to show that although rural-urban migrant students in China display similar problems of educational disadvantage with the global migrant student population to which we alluded above, there are special dimensions of the Chinese scenario which distinguish it from the global community. At this point in the argument there is a salutary reminder to be noted here: namely, that the social phenomenon of internal migration distinguishes China, and the peculiar nature of its problems, from many other countries (Henderson, 2002). In China, recent decades the rapid escalation of economic development has prompted a large number of peasants to seek better employment and education opportunities in urban areas. The term 'migrant population' refers to people who have left their rural regions with their agricultural household registration, and 
who have mostly worked in urban areas for more than six months continuously. 'Internal migrant children'//rural-urban migrant children' were those who were brought into urban schools for transient education (National Bureau of Statistics of China, 2011). The total population of migrants was calculated as 101 million in 2000, increased to 147 million in 2005, and soared to 221 million in 2010.

The integral point which has been neglected in the general discussion of the rural-urban migration in China is the very characteristic which makes the problem of rural-urban migration in China fundamentally unique. What distinguishes the nature of the Chinese migration problem in relation to the problem of educational equity is the governmental decision to institutionalise the internal division of the Chinese population in accord with the enforcement restrictions that are rigidly enforced by the household registration system. Given the range of deliberate structural impediments defined by the government policy on migration, migrant children are almost invariably segregated from the urban mainstream culture and schools, where they have relocated.

In China, the historically household registration system divided Chinese people into agricultural and non-agricultural groups (Wei and Hou, 2010), which fosters a hiatus between rural and urban areas. Because of the formidable barriers imposed by this system, there was little internal migration to urban schools because most migrant students were confined and thus obliged to accept the available education in their own localities. Therefore, migrant children were deprived of the right to equal access to public schools in cities. However, as the process of urbanization continues to burgeon, it is evident that rural-urban migrant people have become the largest social class, which uniquely separated by legislation from both 'rural' and 'urban' people. Furthermore, the household registration system inhibits these people from obtaining equal allocation of access to welfare, employment, and the potential attainment of public goods, particularly when compared to the access to these opportunities afforded to urban residents (Goodburn, 2009). This being so, rural-urban migrant children are classified as being 'out-of-district' children seeking educational opportunities in urban public schools which provide students with better educational opportunities (Xia, 2006).

Table 1 specifies the significant regulations which describe the provision of education for migrant children during the past decades. As indicated in the table, it is clear that the Chinese government has been striving to resolve the problem of how best to accommodate migrant children and cater for their education needs, but they have missed the extent to which the registration policies enacted for migrant children are inevitably 'self-stultifying', thus leading to social exclusion.

Table 1. Regulations related to education for migrant children in1996-2014

Year

Act and Regulation

Content related to migrant children's education

1996 'Measures for the Schooling of Children and Young People in the Urban Migrant Population' (Trial measure).

Municipalities should allow migrant children aged 6-14 to study in full time state-run and privately run schools with the status of temporary students.

2001 'National Program of Action for Child Development in China (2001-2010)'.

1. Migrant children are entitled to 9 years compulsory education;

2. Accommodate migrant children in the urban school system.

2001 'Decision of the State Council on the Development and Reform of Elementary Education'. State-run schools should take the main responsibility for providing migrant children with places. 
'The General Office of the State Council forwarding the Circular of the Opinion of the Ministry of Education and other departments on further improving the education of migrant children'.

Governments of host cities should increase the admission rate of migrant children in compulsory education to the level of local children and make sure private migrant children's schools attain the standards of state schools.

2004 'The Circular of the Ministry of Finance on Regulating Fee Collection and Increasing the Income of Peasants'.

Migrant children should not be asked to pay temporary student fees or school selection fees.

2008 'Circular of the State Council on the Abolition of Tuition and Miscellaneous fees for Students in Compulsory Education in Urban Areas'.

Local government should admit migrant children who meet local criteria to state-run schools in their districts, waive tuition and miscellaneous fees.

2009 'Development and Reform Commission on the Abolition and Suspension of 100 Administrative Fees'.

Migrant children's fees for compulsory education are not required.

2010 'The outline of China's National Plan for Medium and Long term Education Reform and Development (2010-2020)'.

Local government should guarantee migrant children the equal opportunity for admission in compulsory education.

Migrant children can take part in college entrance examination in urban areas.

2014 'National New-type Urbanization Plan (2014-2020'

60 percent of Chinese people living in cities by 2020.

Grant 100 million migrants with 'urban household designation'.

'Opinions on Further Promotion of the Reform of Household Registration System'

There is no difference between the rural and urban residence and moreover, rural-urban migrant people are encouraged to live in urban areas.

Overall, the table shows that the Chinese government has gradually introduced policies to protect the educational rights of migrant children's education in urban schools. Since 2000, the government began to provide education within the public school system for migrant children, with the system of private education playing a complementary role of providing educational opportunity for these children. In particular, during the course of the 2014 year, the Chinese government issued several proposals to break down the sociopolitical barriers that have traditionally characterized the nationwide household registration system in some cities (Chen, 2013). As a consequence, the household registration policy would gradually no longer designate demographic divisions of educational apartheid in terms of agricultural and non-agricultural divisions.

Currently, migrant children are mainly enrolled in two types of schools in urban areas including: private migrant children's schools (migrant schools) and public integrated schools (public schools). As the educational system in public schools is mainly designed to serve urban children with non-agricultural household registration, migrant schools are solely formed for rural-urban migrant children in urban areas. Specifically, urban public schools are allocated resources for urban children who hold the non-agricultural registration status within the school district (Wei and Hou, 2010). Migrant children's educational funding, however, remains allocated to their family's rural homes, despite their families have migrated to an urban area. Urban public schools, which were sponsored and managed by local Ministry of Education, do not have allocated educational resources for these 'out-of-district' children. Therefore, the influx of increasing migrant population resulted in a shortage of educational funds in urban areas. The capacity of the local educational authorities was undermined to accommodate equitably the educational needs for all students, migrant and urban. This being so, some urban public schools intend to recruit 
migrant children on the condition that they can meet the requirements of extra high tuition fees, as called 'donations' (Goodburn, 2009). Migrant families with a higher SES may have opportunities to send their children to urban public schools on such a high price. Nevertheless, for the majority of migrant children who hold the agricultural household registration with a lower SES, fewer opportunities are doubtless available for enrolment in urban public schools $(\mathrm{Li}, 2012)$.

To tackle the problems of migrant children's education, private migrant schools have been established to provide educational opportunities for children. This type of school does not required household registration and expensive school admission, but on the price of low school quality. The low school tuition fees and no government fund made the migrant schools lack of educational resources, including poor school facilities, unqualified teachers, and low achievement levels (Lai et al., 2014). It is reported thousands of migrant schools have been opened among Chinese cities in 2000-2008. Despite these disadvantages, migrant schools do 'open the gate' for migrant children to receive education in urban areas.

Given a greater awareness of these inequities, several regulations and laws have been promulgated to facilitate the access for migrant children to urban public schools. The State Council circulated an official notice of 'Decision on the Development and Reform of Elementary Education", and push local governments to provide school education for all children under their jurisdictions (State Council, 2001). This policy was based on the following two premises, colloquially known as the 'Two Mainlines': (1) the "education of migrant children is mainly the responsibility of the recipient city" and (2) "migrant children should be educated mainly in urban public schools". This national directive urged every recipient city to take immediate action to deal with the issue of migrant children. Even so, there have been evidenced reports that children migrating from rural regions were excluded from urban public schools at the earlier years, and the majority of migrant students received education in the segregated migrant schools (Wang and Holland, 2011).

Since 2008, some cities such as Beijing and Shanghai embarked on a reform of migrant children's schools and strived to improve the education quality for all migrant students. For example, Shanghai government developed the 'Three-Year Action Plan (2008-2010) for Compulsory Education of Migrant Children' (Shanghai Ministry of Education 2008). With the three year plan, public schools were expanded in terms of class size; migrant schools have been reconstructed and managed by local government. According to the statistics, the proportion of migrant children enrolling in public schools has been augmented to about 60 percent in Beijing, which, as the Capital of China is extremely densely populated. Shanghai, as another of the largest cities in China, accommodated $53.9 \%$ of migrant students (approximately, 208 thousand) in 2008; with the figure increasing significantly to 71.4 percent, thus (approximately, 336 thousand migrant children) studying in integrated public schools in 2010 (Central government of China, 2011). However, these initiatives taken among Chinese cities differ. For example, Guangzhou city, accommodated less than 33 percent of migrant students (or only 109 thousand) in public schools; some cities in middle China (e.g., Chengdu, Wuhan, and Chongqing) have not implemented the policies effectively.

To determine more accurately the specific disparities in performance outcomes, educational research scholars are now beginning to gather and analyse the preliminary evidence from schools which serve to contrast any perceived level of inequity which results from migrant students' disadvantaged learning environments in segregated migrant schools in comparison to public schools. Many studies have elaborated the implications of Chinese segregation policy and determined its influence on performance outcomes of migrant students enrolled in segregated migrant schools, in contrast to public schools (Lai et al., 2014). This contrast, we submit, serves to provide a salient example of the paramount importance of acknowledging the problems of purported inequities, so that everyone involved is better apprised of the facts which assist in their resolution.

The Chinese educational system relies on test scores as the primary criterion in the selection process for student academic promotion, college entrance, and employment. Therefore, for migrant families, the academic outcomes of migrant children are essential conditions to be satisfied to secure any substantial hope for their upward mobility and opportunity for future success. This paper then focuses on studies related to the education of migrant children in urban areas, with particular attention on Chinese studies concerned to examine the discrepancies exhibited by migrant children's school outcomes, depending upon the schooling context in the following section.

\section{The Impact of School Segregation on the Educational Outcomes of Migrant Children}

As we have seen above, there is a growing body of scholarly literature which shows that school segregation features a decisive structural factor in explaining certain inequities in educational outcomes amongst migrant individuals ( $\mathrm{Lu}$ and Zhou, 2013). Before we can proceed further, however, we submit that there is a radical 
ambiguity in the interpretation sometimes given to the term 'segregation' which has served to conflate subtleties of significance of relevance to the inequity argument that remain badly in need of differentiation. Part of our immediate task will thus be to make these distinctions more pellucid than has yet been the case. Coleman (1966) studied on the impact of ethnic and socioeconomic school composition on students' academic achievement levels. The results show the effect of segregation on migrant students' academic achievement. Despite the absence of a well-articulated account of the term 'segregated', and the presence of misleading ambiguities which have arisen out of it, on the one hand, a general consensus has nevertheless emerged that while there are certain benefits associated with students attending diverse schools. On the other hand, it is also evident to find an array of adverse effects confronting students who are segregated in schools where poor and minority students are concentrated (Davis-Kean, 2005).

Although we concede that there is a truth expressed here, we argue that it is not the whole truth, as the problem of poor test results cannot be causally reduced and coherently explained by blaming 'segregated schooling'. It is incontestable that, for example, in Australia 'private schools' are in essence, an institutional 'form' of segregation with a higher SES. A considerable literature has accumulated to show that the academic performance of private school pupils is generally superior to students attending local public schools. Similarly, there are a modest number of so-called segregated schools which actually focus on pupils from a lower SES. In many of these cases the performance levels enjoyed by such students are outstanding. So, the problem of school-based inequities and disparate academic performance levels between segregated and non-segregated students should not be construed as an 'exclusive disjunction', in the sense that if a student were enrolled in a segregated school, she would necessarily be disadvantaged, while by parity of reasoning, any student is equally advantaged by being in a public school. The point is that the term 'segregated' is not connotatively monolithic, but rather multifaceted.

Therefore, it would be misleading to imply that the concept of segregated schools can be construed as the causally defining and predominant factor in determining the likelihood of failure, or diminished performance. The issue of inequity does not depend solely on whether a school is segregated, but rather on whether it is grounded in a philosophy of education and the provision of educational leadership which guides its students to discover their true potential and the best version of themselves. The question is not so much whether the school is segregated, but whether it has good leadership, coupled with committed and talented/skilled teachers. It also helps for a school to have sufficient funding to sustain innovative pedagogic programs, along with the associated costs of the equipment required to accompany it. Whether a segregated school can survive depends also on whether its staff is well-educated, experienced, motivated and patiently devoted to the noble task of teaching. Therefore, the analysis of these issues needs to be much more precise with regard to the peripheral variables which give sense and substance to the concept of a 'segregated school'. The explanation of 'segregated school' in this section, aims to bring an insight of monumental importance in advancing a deeper understanding of how best to extirpate the inequities which fester in the context of Chinese migrant education.

Once the ambiguities of definition have been resolved, however, it is clear that certain of these variables can be identified. For example, we submit that studies have now clearly shown that migrant students who attend schools with a greater composition of children from higher SES background do generally perform better academically than those children who do not (Guo, 2011). In contrast, that is to say, segregated 'minority' schools, without this variable tend to produce students who display lower levels of academic achievement, fewer job opportunities, a reluctance to pursue demographically integrated relationships in future life (Linn and Welner, 2007). In addition, there are several studies on the state of mental health of migrant children from segregated migrant schools, where the majority of Chinese students from lower socioeconomic backgrounds are more likely to suffer some degree of mental/psychological health problems (Tao et al., 2004). Some research reveals that many of these students will inevitably develop poor learning habits (Lai et al., 2014). In contrast, migrant children in public schools had a better adaptive capacity than that of students in segregated migrant schools (Shen, 2008). Moreover, migrant children enrolled in public schools express a higher level of overall satisfaction with their school learning environment than do migrant school students in segregated schools (Xie, 2007); Migrant children in integrated public schools exhibit higher levels of academic achievement than do migrant students in segregated migrant schools, but no significant difference was found between migrant students and local children within public schools (Lu and Zhou, 2013).

Given the increasing recognition of the difference in performance outcomes between migrant children in segregated schools and those in integrated schools, the literature on school segregation and assimilation perspective has dominated much of the sociological thinking on the subject for the larger part of this century. Scholars have noted that rather than a 'straight-line' course of migrant adaption, multiple pathways to 
assimilation are critical, depending on their origins, socioeconomic status, contexts of reception, and family resources, both social and financial. Based on the growing body of literature on migrant assimilation in recent decades, the next section elaborates the assimilation experiences of migrants which reflect variegated and diverse pedagogic opportunities.

\section{Discussion of School Segregation and Segmented Assimilation of Chinese Migrant Children}

In the context of our examination of the issues surrounding the debate on immigrant equity, one theory that has emerged out of this discourse is known as 'segmented assimilation theory' (Portes and Zhou, 1993). The central assumption is that there is a natural process by way of which diverse ethnic groups come to share a common culture and finally to gain equal access to the opportunity structure of society. However, depending on the migrant's national origins, socioeconomic status, contexts of reception in the destination cities, and family social and financial resources (Zhou, 1997), new immigrants may assimilate with different groups, and consequently, have taken divergent assimilation paths. Portes and Zhou (1993) have illustrated three possible patterns of adaptation that are most likely to occur among contemporary immigrants.

One of them replicates the time-honored portrayal of growing acculturation and parallel integration into the white middle-class; a second leads straight into the opposite direction to permanent poverty and assimilation into the underclass; still a third associates rapid economic advancement with deliberate preservation of the immigrant community's values and tight solidarity (p. 82).

One aspect of the problem that arises here relates to several major factors concerning the disparate nature of the school context, itself. An extensive literature connects the widespread school segregation in the United States to inequality in educational attainment, suggesting that students in segregated schools tend to perform less well than other children, and are more likely to drop out of school and engage in risky and mischievous behaviors (Wells and Crain, 1994). In the words of Portes and Rumbaut (2001, p. 59):

[A major] challenge confronting children of immigrants is that the social context they encounter in American schools and neighborhoods may promote a set of undesirable outcomes such as dropping out of school, joining youth gangs, or participating in the drug subculture.

Other scholars argue that structural factors include racial status, family socioeconomic backgrounds, and place of residence (Nordin, 2013; Willibrord and Zenderen, 2009). Family socioeconomic status shapes the immediate social conditions for adaptation, which we believe is one of the most crucial factors. The reason for this is because it determines the environment in which children live, the quality of schools which they are likely to attend, and the group of peers with which they are likely to associate. Moreover, the significance of class has a direct implication on the adaptation outcomes of immigrant children. Those from middle-class backgrounds are generally more able to benefit from financially secure families, good schools, and other supportive formal and informal organizations, each of which contributes to ensure better opportunities for a successful life for them. In contrast, children with poorly educated and unskilled parents often find themselves growing up in underprivileged neighborhoods, subject to poverty, poor schools, violence and drugs, and a generally disruptive social environment (Portes et al., 2005). These children suffer from unequal distribution of educational resources, which in turn seriously curtails their chances in life, trapping them further in isolated ghettos (Levy and Schady, 2013).

Chinese rural-urban migration shares significant structural elements with migrant experiences in other societies, where these elements often intersect with race, ethnicity, and citizenship status. In this respect, the extensive literature on children of immigrants in western countries, especially the United States, can inform studies of migrant children in China. The concept of 'segmented assimilation' has accordingly been considered to facilitate a typology of vulnerability and inequity affecting differentially diminished outcomes for Chinese migrant groups. Some studies have applied this mechanism in the context of Chinese internal migration, and it was revealed that the same sort of educational inequities result in such discriminatory situations ( $\mathrm{Lu}$ and Zhou, 2013).

Therefore, the interconnected argument of our study has accumulated sufficient evidence to confirm that there exist divergent assimilation paths for these new migrant groups in China. One group exhibits a disposition to a high SES, while the other has a low SES, thereby disposing the former group towards upward assimilation, while the other is disposed towards downward assimilation. During their period of segregated education from urban mainstream schools, migrant students in urban areas integrate only peripherally into urban society. This is reflected not only by the achievement level hiatus which exists between the two migrant groups, but is strongly exemplified in the ever growing gap between segregated migrant students and urban children, as the grade levels increase. As we witnessed in the body of the literature above, the fact is that migrant students in desegregated schools achieved as favorable test results as did urban children. The findings prove that it is suffice to ensure that 
migrant children with low SES have the intellectual gifts and motivation to adapt effectively to urban culture, as long as they are provided with integrated education. Therefore, we believe that given access to public school education, migrant school students should in principle be sufficiently able to improve their academic outcomes to a level of achievement.

As a result, we submit that the goal of school integration for migrant children, not school segregation, should become one of the most important policies of the Chinese government. The government gradually fostered an awareness of the potentially negative influence of segregated education on migrant youth and improved migrant students' access to public schools significantly, such as 'Shanghai reform Model'. However, we cannot deny the current situation of migrant students in segregated migrant schools still exposes them to disadvantage in the majority of cities across China (Chen, Wang and Wang, 2009). Take Shanghai, for example, which, as we observed earlier, is one of China's largest metropolitan cities, which it is politically portrayed to represent a 'high quality' school system within China. Yet the reason for this is because it is the only participant city in the Program for International Student Assessment (PISA), and thus the only one to achieve top world-ranking results (Sellar and Lingard, 2013). Lamentably, however, the large population of migrant students which exists in Shanghai has recently been segregated from the Shanghai urban educational system, so that migrant test results are not included in the program sampling. It is hard not to conclude, therefore, that assessments of the program's success which fail to include the test results of the city's segregated migrant students are anything other than intrinsically misleading, and thus exaggerate the reality of China's educational success. That the inaccurate reflection exposed here still persists, clearly betrays the deeper truth that given its huge numbers of migrant children, the local government of Shanghai has not yet shown itself to be successful in accommodating migrant children within the arena of public educational resources, which would otherwise have afforded them the opportunities for improved academic success they equitably deserve (Wei and Hou, 2010).

Moreover, the impact of school segregation has made migrant children at disadvantage, which may be felt irrevocably on the next generation across the entire nation (Lan, 2014). Although the latest policy strived to reform household registration system, there remain roughly two-thirds of migrant population will be excluded from city-resident status by 2020. This being so, there exists an increasing belief among many scholars and policy makers as well that the integration of migrant students into public schools is the most effective route to the equalisation of educational resources, and thus equitable opportunities across rural and urban groups (Qian and Walker, 2015). Another important point is that migrant students with low SES live on the city fringes, literally known as 'villages in the city' in impoverished urban areas. Chinese central government has enhanced social support for these migrant families through strengthening social solidarity as a method of developing community services ( $\mathrm{Li}$ and Placier, 2015; Wen and Hanley, 2016). With regard to education, migrant children who attend desegregated schools also need to have access to social networks and personal friendships that are likely to have a beneficial socioeconomic influence on their lives.

In the light of our analysis of the existing performance inequities which characterise the experience of migrant students enrolled in segregated schools of lower socio-economic background, we fervently urge that the Chinese government encourage and support more research to determine the extent to which these profound discrepancies in educational opportunity still exist between segregated migrant and public schools, thereby serving to disadvantage, possibly irremediably, the academic potential of migrant students sequestered in segregated schools. Once more of this information is accurately gathered and analysed, educational leaders will be in a much better position to monitor and in turn overcome the lack of equal opportunities which presently impede the access of migrant students to the quality education capable of helping them to maximise their true potential.

\section{Conclusion and Implications}

This paper examines school segregation policy and its educational ramifications for internal migrant children in a Chinese urban setting. The results show the changes and features of policies towards segregation of the migrant population in the recent decades, and the negative influence in turn engendered inequities in academic performance which could plausibly have been avoided. This study, therefore, indicates that the Chinese government's current policy of segregating migrant students' education does not effectively deliver high quality education to migrant children. In comparison to the delivery available in urban public schools, the disparities in segregated schools remain an especially formidable barrier to provide opportunities of academic promotion, social assimilation and future success for migrant children.

The analysis results provide implications for migrant children's education and reflections of policies, in order to improve current educational situation of migrant children. Firstly, this paper suggests that it is necessary to enlarge the opportunities for migrant children to study in desegregated public schools, rather than merely implementing 
segregation policy to sequester them in migrant schools. Second, the educational quality of segregated migrant schools needs decisively to be improved with balance more equitably the distribution of educational resources. Above all, it is of paramount importance to make clear that it is no part of our purpose to deny the value of migrant schools, as their proliferation has incontestably facilitated the rapid increase of migrant children to urban schools within a short time frame. However, the deeper point we have been concerned to make in this paper is promoting segregated education policy into a more inclusive environment for all children by the China government.

\section{References}

Agirdag, O., Avermaet, P., \& Houtte, M. (2013). School segregation and math achievement: A mixed-method study on the role of self-fulfilling prophecies. Teachers College Record, 115(3), 1-50.

Chen, X., Wang, L., \& Wang, Z. (2009). Shyness-sensitivity and social, school, and psychological adjustment in rural migrant and urban children in China. Child Development, 80(5), 1499-1513. https://doi.org/10.1111/j.1467-8624.2009.01347.x

Clotfelter, T. (1999). Public school segregation in metropolitan areas. Land Economics, 75(4), 487-504. https://doi.org/10.2307/3147061

Davis-Kean, E. (2005). The influence of parent education and family income on child achievement: the indirect role of parental expectations and the home environment. Journal of Family Psychology, 19(2), 294-304. https://doi.org/10.1037/0893-3200.19.2.294

Dronkers, J., \& Levels, M. (2007). Do school segregation and school resources explain region-of-origin differences in the mathematics achievement of immigrant students? Educational Research and Evaluation, 13(5), 435-462. https://doi.org/10.1080/13803610701743047

Frankenberg, E., Genevieve, S., \& Jia, W. (2010) Choice without equity: charter school segregation and the need for civil rights standards. Civil Rights Project/Proyecto Derechos Civiles.

Garcia, R. (2008). The Impact of school choice on racial segregation in charter schools. Educational Policy, 22(6), 805-829. https://doi.org/10.1177/0895904807310043

Goodburn, C. (2009). Learning from migrant education: A case study of the schooling of rural migrant children in Beijing. International Journal of Educational Development, 29(5), 495-504. https://doi.org/10.1016/j.ijedudev.2009.04.005

Guo, J. (2011) Family and parent correlates of educational achievement: migrant children in China. Asian Social Work \& Policy Review, 5(2), 123-137. https://doi.org/10.1111/j.1753-1411.2011.00054.x

Henderson, V. (2002). Urbanization in developing countries. The World Bank Research Observer, 17(1), 89-112. https://doi.org/10.1093/wbro/17.1.89

Iversen, V. (2002). Autonomy in child labor migrants. World Development, 30(5), 817-834. https://doi.org/10.1016/S0305-750X(02)00007-4

Kang, S. (2010) Multicultural education and the rights to education of migrant children in South Korea. Educational Review, 62(3), 287-300. https://doi.org/10.1080/00131911.2010.503599

Lai, F., et al. (2014). The education of China's migrant children: The missing link in China's education system. $\begin{array}{llll}\text { International Journal of Educational Development, } & 37(1), & \text { 68-77. }\end{array}$ https://doi.org/10.1016/j.ijedudev.2013.11.006

Lan, P. (2014) Segmented incorporation: The second generation of rural migrants in shanghai. China Quarterly, 217, 243-265. https://doi.org/10.1017/S030574101300146X

Levy, S., \& Schady, N. (2013). Latin America's social policy challenge: education, social insurance, redistribution. The Journal of Economic Perspectives, 27(2), 193-218. https://doi.org/10.1257/jep.27.2.193

Li, N., \& Placier, P. (2015). Migrant and non-migrant families in Chengdu, china: Segregated lives, segregated schools. Social Sciences, 4(2), 339-360. https://doi.org/10.3390/socsci4020339

Lialiugene, I., \& Rupshene, L. (2008). The effect of parents' labor migration on the socialization of adolescents. Russian Education \& Society, 50(11), 6-19. https://doi.org/10.2753/RES1060-9393501101

Linn, L., \& Welner, G. (2007). Race-conscious policies for assigning students to schools: social science research and the supreme court cases. committee on social science research evidence on racial diversity in schools. National Academy of Education.

Liu, J., \& Jacob, J. (2013). From access to quality: migrant children's education in urban China. Educational 
Research for Policy and Practice, 12(3), 177-191. https://doi.org/10.1007/s10671-012-9136-y

Lu, Y., \& Zhou, H. (2013). Academic Achievement and Loneliness of Migrant Children in China: School Segregation and Segmented Assimilation. Comparative education review, 57(1), 85-116. https://doi.org/10.1086/667790

Nordin, M. (2013). Immigrant school segregation in Sweden. Population Research and Policy Review, 32(3), 415-435. https://doi.org/10.1007/s11113-013-9271-z

Portes, A., Fernández-Kelly, P., \& Haller, W. (2005). Segmented assimilation on the ground: The new second generation in early adulthood. Ethnic and Racial Studies, 28(6), 1000-1040. https://doi.org/10.1080/01419870500224117

Portes, A., \& Zhou, M. (1993). The new second generation: Segmented assimilation and its variants. The Annals of the American Academy of Political and Social Science, 530(1), 74-96. https://doi.org/10.1177/0002716293530001006

Qian, H., \& Walker, A. (2015). The education of migrant children in Shanghai: The battle for equity. International Journal of Educational Development, 44, 74-81. https://doi.org/10.1016/j.ijedudev.2015.07.009

Sellar, S., \& Lingard, B. (2013). Looking East: Shanghai, PISA 2009 and the reconstitution of reference societies in the global education policy field. Comparative Education, 49(4), 464-485. https://doi.org/10.1080/03050068.2013.770943

Shen, Z. (2008). Research on school adaption of rural migrant workers' children in Shanghai. Education Development and Research, 10, 62-65.

Tao, H., et al. (2004). Comparison of the mental health status between migrant and local high school students in Beijing. Chinese Journal of Special Education, 51(9).

Wei, J., \& Hou, J. (2010). The Household Registration System, Education System, and Inequalities in Education for Migrant Children. Chinese Education \& Society, 43(5).

Wells, S., \& Robert, C. (1994). Perpetuation theory and the long-term effects of school desegregation. Review of Educational Research, 64(4), 531-555. https://doi.org/10.3102/00346543064004531

Willibrord, G., \& Zenderen, K. (2009). Segmented assimilation in the Netherlands? Young migrants and early school leaving. Ethnic and Racial Studies, 32(8), 1470-1488. https://doi.org/10.1080/01419870902763860

Xia, C. (2006). Migrant children and the right to compulsory education in China. Asia-Pacific Journal on Human Rights \& the Law, 7(2), 29-74. https://doi.org/10.1163/157181506779891465

Xie, Y. (2007). A Survey Report on the Growth Education of the Migrant Workers' Children in Wuhan. Journal of Hubei University Philosophy and Social Science, 34(6), 13-17.

Zhou, M. (1997) Segmented assimilation: Issues, controversies, and recent research on the new second generation. International migration review, 975-1008. https://doi.org/10.2307/2547421

\section{Copyrights}

Copyright for this article is retained by the author(s), with first publication rights granted to the journal.

This is an open-access article distributed under the terms and conditions of the Creative Commons Attribution license (http://creativecommons.org/licenses/by/4.0/). 